13

\title{
Многослойные полевые эмиттеры, изготовленные из приведенных в контакт нанослоев гафния и платины
}

\author{
() Г.Г. Соминский, ${ }^{1}$ В.Е. Сезонов, ${ }^{1}$ С.П. Тарадаев, ${ }^{1}$ С.Н. Вдовичев ${ }^{2}$ \\ ${ }^{1}$ Санкт-Петербургский политехнический университет Петра Великого, \\ 195251 Санкт-Петербург, Россия \\ ${ }^{2}$ Институт фозики микроструктур РАН, \\ 603950 Нижний Новгород, Россия \\ e-mail: sominski@rphf.spbstu.ru
}

(Поступило в Редакцию 14 марта 2018 г.)

Изучены полевые эмиттеры нового типа, изготовленные из приведенных в контакт нанослоев гафния и платины. Проведены расчеты, позволяющие оптимизировать характеристики многослойных катодов. Экспериментально измерены эмиссионные характеристики катодов. Получены токи полевой эмиссии до 2-2.5 mA при плотности тока ориентировочно до $200 \mathrm{~A} / \mathrm{cm}^{2}$. Продемонстрирована возможность существенного увеличения полного достижимого тока полевой эмиссии в результате сложения токов с нескольких многослойных систем.

DOI: $10.21883 / J T F .2019 .01 .46976 .112-18$

\section{Введение}

Полевые эмиттеры привлекательны для использования в миниатюрных, но высоковольтных электронных приборах. Их преимущества по сравнению с термокатодами определяются прежде всего тем, что они не требуют накала и практически безынерционны. Однако для обеспечения достаточно интенсивной полевой эмиссии необходимо создать поля у их поверхности порядка или даже более $(2-4) \cdot 10^{7} \mathrm{~V} / \mathrm{cm}$. Для достижения таких полей при умеренных рабочих напряжениях обычно на поверхности эмиттера создают системы выступов, обеспечивающих значительное усиление электрического поля. В условиях технического вакуума в высоковольтных электронных приборах усиливающие поле структуры разрушаются под действием бомбардировки ионами остаточного газа и/или большими по величине пондеромоторными силами, что приводит к деградации катода и выходу его из строя.

Ранее нами было обнаружено, что необходимые для эмиссии поля могут существовать у контакта материалов с сильно отличающимися значениями работы выхода $е \varphi$ [1]. Были созданы и исследованы многослойные наноструктурированные катоды из разных материалов [2-4], отличающихся разностью работ выхода $\Delta e \varphi$ приведенных в контакт слоев, и разным количеством $N$ пар слоев. Эмиссионная эффективность катодов увеличивалась с ростом $\Delta e \varphi$. Наибольшие токи были получены с помощью катодов из приведенных в контакт иттербия $\left(e \varphi_{\mathrm{Yb}} \approx 3.1 \mathrm{eV}\right)$ и углерода $\left(e \varphi_{\mathrm{C}} \approx 4.7 \mathrm{eV}\right)$. При фиксированном значении $\Delta e \varphi$ токи полевой эмиссии возрастали с увеличением количества пар слоев в катоде. Однако в исследованиях было установлено, что структуры с количеством пар слоев $N>40-50$ непрочны и быстро разрушаются в процессе эксплуатации, видимо, из-за уменьшения прочности при превышении некоторого характерного значения суммарной толщины структуры $d_{\Sigma} \sim 300-400 \mathrm{~nm}$. В настоящей работе исследованы привлекательные из-за большей по сравнению c $\mathrm{Yb}-\mathrm{C}$-катодами разницы работ выхода $\Delta e \varphi \approx 1.8 \mathrm{eV}$ многослойные эмиттеры, изготовленные из приведенных в контакт нанослоев гафния $\left(e \varphi_{\mathrm{Hf}} \approx 3.5 \mathrm{eV}\right)$ и платины $\left(e \varphi_{\mathrm{Pt}} \approx 5.3 \mathrm{eV}\right)$. Слоистые $\mathrm{Hf}-\mathrm{Pt}-$ катоды изготавливались, как и ранее [2-4], с использованием достаточно оперативного и простого метода магнетронного напыления.

\section{Оптимизация структуры многослойного Hf-Pt-эмиттера}

Как показали выполненные нами ранее исследования [3,4], при создании многослойных катодов необходимо прежде всего оптимизировать толщины слоев приводимых в контакт материалов. В настоящей работе, как и ранее $[3,4]$, для решения этой задачи с использованием программы Comsol Multiphysics рассчитывались токи полевой эмиссии при разных значениях толщины слоев гафния $\left(d_{\mathrm{Hf}}\right)$ и платины $\left(d_{\mathrm{Pt}}\right)$, а также при разном количестве $N$ пар слоев. При оптимизации структуры $\mathrm{Hf}-\mathrm{Pt}-$ катодов учитывалось существование переходной области между контактирующими слоями, состоящей из смеси этих материалов. Формирование таких переходных областей наблюдалось ранее при создании с помощью магнетронного напыления многослойных систем, например, элементов рентгеновской оптики [5-7]. В литературе отсутствует информация о толщине переходного слоя для используемой нами пары материалов $\mathrm{Hf}-\mathrm{Pt}$, однако для других материалов эта величина меняется в сравнительно узких пределах $0.3-0.8 \mathrm{~nm}[5-7]$. 


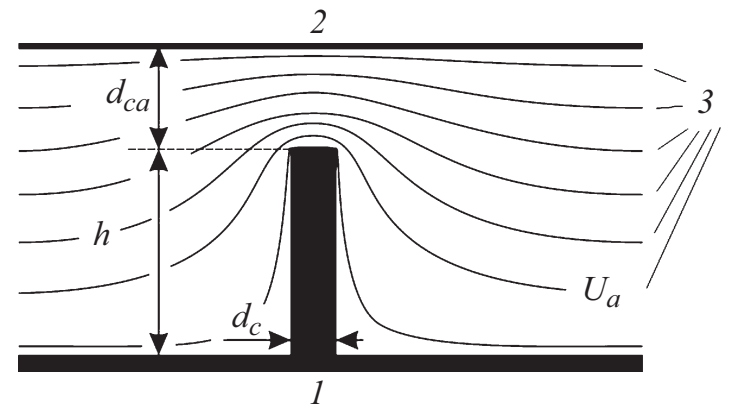

Рис. 1. Схематическое изображение диодной системы и полученных в расчете линий постоянного потенциала: 1 катод, 2 - анод, 3 - эквипотенциали; $d_{c}$ и $h-$ толщина и высота катода, $d_{c a}-$ расстояние между катодом и анодом.

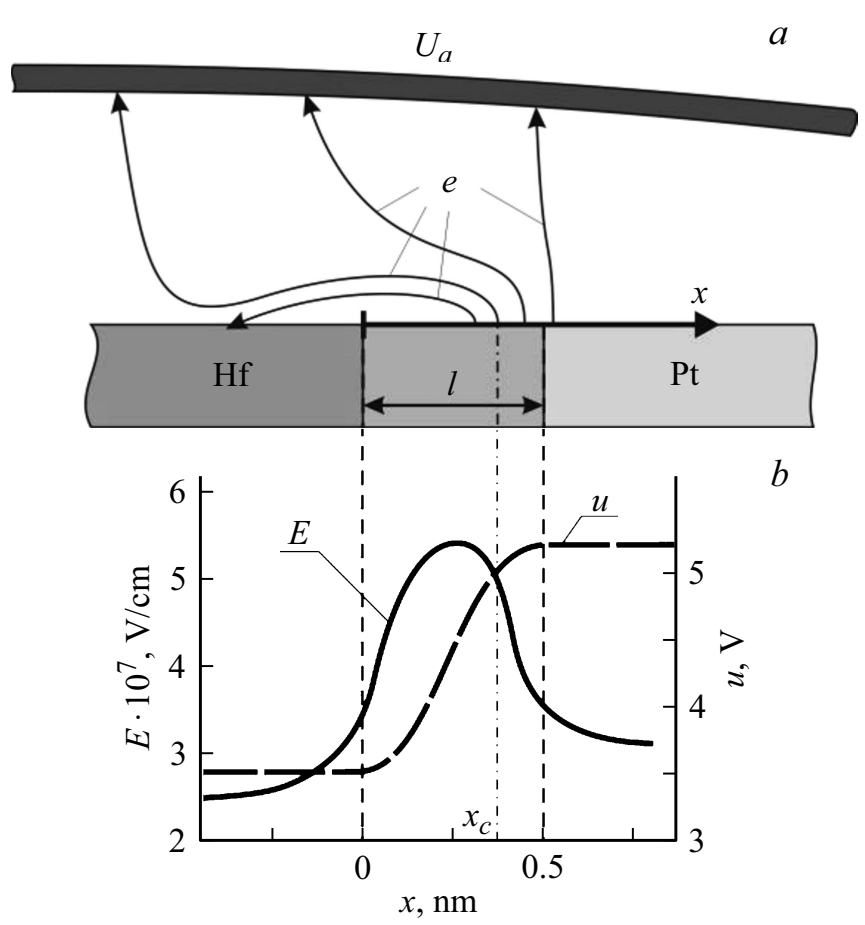

Рис. 2. $a-$ схематическое изображение сечения модельного диода вблизи контакта $\mathrm{Hf}$ с $\mathrm{Pt}(e-$ траектории электронов, $l$ - ширина переходной области); $b$ - распределение поля $E$ и потенциала $u$ по поверхности катода.

Расчет характеристик многослойного катода велся поэтапно. Сначала без учета контактных полей у торца слоистого катода определялись распределения потенциала для диодной системы, схематически изображенной на рис. 1, при разных значениях разности потенциалов $U$ между катодом и анодом, разных значениях толщины $\left(d_{c}\right)$ и высоты $(h)$ катода и фиксированном значении расстояния между катодом и анодом $d_{c a}=1 \mathrm{~mm}$. Затем строился „модельный диод“ с анодом, совпадающим с одной из эквипотенциалей, рассчитанных на предыдущем этапе, и потенциалом $U_{a} \ll U$, задавалось распределение потенциала у поверхности многослойной катодной структуры с учетом контактных полей и поля, обусловленного напряжением $U_{a}$, рассчитывались распределения электрического поля $E$ и траектории электронов в области между катодом и анодом модельного диода. На рис. 2 схематически показана конфигурация модельного диода у одной из ячеек слоистой структуры. Анод модельного диода располагался на расстоянии от катода, много меньшем $1 \mathrm{~mm}$, но существенно превышающем поперечный размер ячейки многослойной структуры, например, на расстоянии 200-300 nm, т.е. в области, где поля, обусловленные контактной разностью потенциалов, малы по сравнению с внешним полем.

Распределение потенциала $u$ вблизи контакта материалов с разной работой выхода задавалось в расчетах соотношением

$$
u(x)=e \varphi_{\mathrm{Hf}}+(\Delta e \varphi / 2)[1 \pm \cos (\pi x / l)]
$$

где $x$ - координата вдоль поверхности катода, $е \varphi_{\mathrm{Hf}}-$ работа выхода гафния, $\Delta e \varphi-$ разность работ выхода приведенных в контакт материалов, $l$ - ширина переходной области (см. рис. 2). Здесь учтено, что распределение работы выхода монотонно меняется в переходной области от $е \varphi_{\mathrm{Hf}}$ до работы выхода платины $е \varphi_{\mathrm{Pt}}$.

На основании полученных данных о распределении электрического поля у катода с использованием формулы Фаулера-Нордгейма определялись распределение плотности тока эмиссии по поверхности катода и полный ток I на анод. В расчетах учитывалось, что анода достигают электроны только с участка катода у контакта Hf и Pt с координатами $x \geq x_{c}$ (см. рис. $2, b$ ).

Токи рассчитывались для Hf-Pt-эмиттера, включающего 20 пар слоев, при разных значениях толщины слоев гафния $\left(d_{\mathrm{Hf}}\right)$ и платины $\left(d_{\mathrm{Pt}}\right)$, а также ширины переходной области $l$. На рис. 3 показана типичная зависимость тока $I$ от величины $l$, полученная при $U=6 \mathrm{kV}$ для структуры со слоями гафния и платины толщиной соответственно $d_{\mathrm{Hf}}=10 \mathrm{~nm}$ и $d_{\mathrm{Pt}}=2 \mathrm{~nm}$. На рис. $4, a$ приведены зависимости эмиссионного тока от толщины $d_{\mathrm{Pt}}$ слоев платины, полученные при двух значениях толщины слоев гафния $d_{\mathrm{Hf}}$. Зависимости $I\left(d_{\mathrm{Hf}}\right)$, полученные при двух значениях $d_{\mathrm{Pt}}$, показаны на рис. $4, b$.

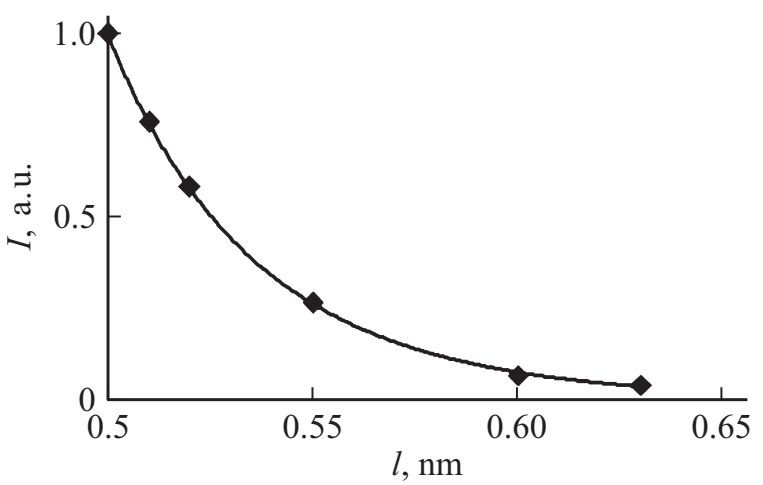

Рис. 3. Зависимость от ширины переходной области $l$ тока эмиссии $I$ многослойной системы, состоящей из $N=20$ пар слоев; $d_{\mathrm{Hf}}=10 \mathrm{~nm}, d_{\mathrm{Pt}}=2 \mathrm{~nm}, U=6 \mathrm{kV}$. 
Из расчетов видно, что для структуры, включающей 20 пар слоев, увеличение толщины слоев платины $d_{\mathrm{Pt}}$ при фиксированной толщине слоев гафния $d_{\mathrm{Hf}}$ ведет к быстрому падению эмиссионного тока. Увеличение же толщины слоев гафния при $d_{\mathrm{Pt}}=$ const сопровождается быстрым ростом эмиссионного тока, во всяком случае в интервале $d_{\mathrm{Hf}} \leq 20-25 \mathrm{~nm}$.

Из проведенного расчета следует очевидный казалось бы вывод, что для получения максимального тока при минимальной толщине слоев платины толщину слоев гафния необходимо выбирать равной или больше 20-25 nm. Однако такой вывод может оказаться неверным, если учесть, что суммарная толщина многослойного катода не должна превышать 300-400 nm. Действительно, если при заданной суммарной толщине слоистой структуры $d_{\Sigma}$ и при фиксированной толщине слоев платины $2 \mathrm{~nm}$ оптимизировать толщину слоев гафния при произвольном количестве пар слоев $N$ в структуре, расчеты дают другой результат, который иллюстрируют характеристики, приведенные на рис. 5.
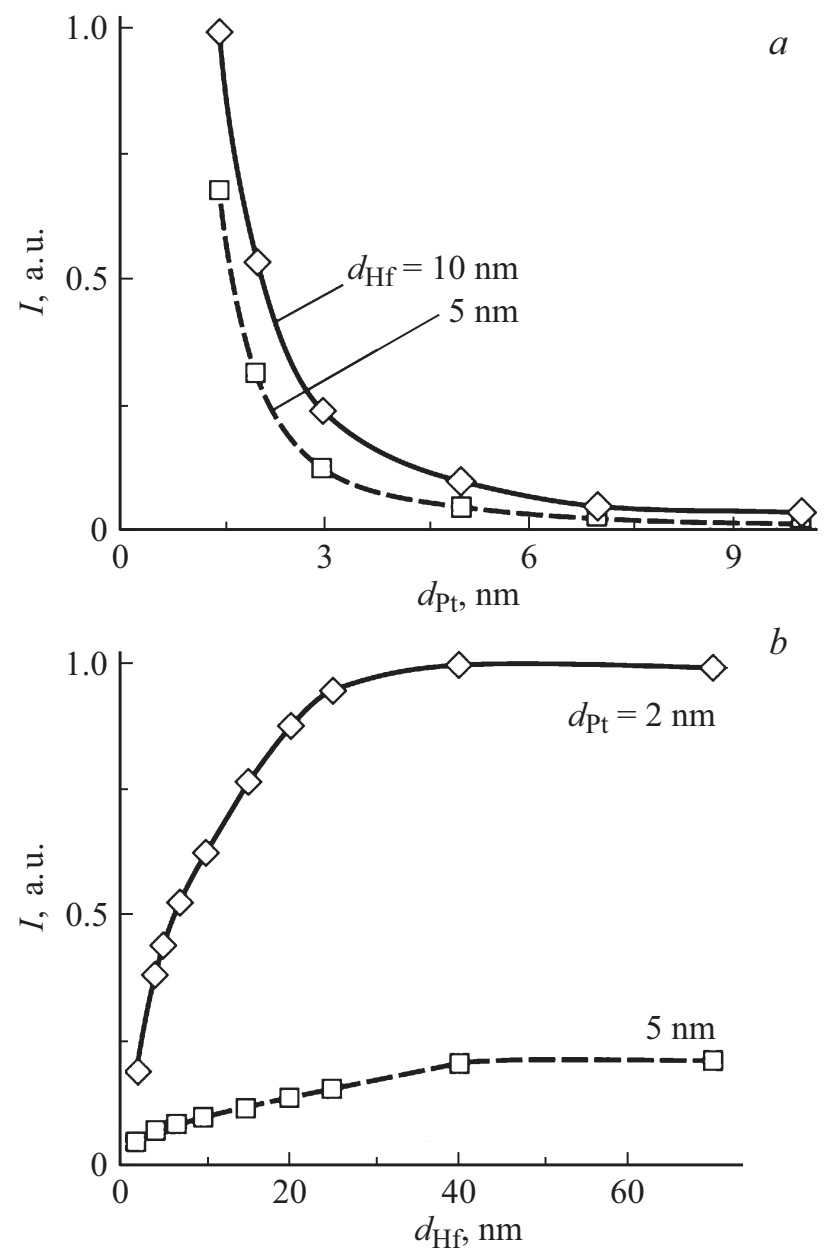

Рис. 4. $a$ - зависимости тока эмиссии $I$ многослойного катода от толщины слоев платины $d_{\mathrm{Pt}}$, рассчитанные при фиксированных значениях толщины слоев гафния $d_{\mathrm{Hf}} ; b-$ зависимости $I\left(d_{\mathrm{Hf}}\right)$, полученные при постоянных значениях толщины слоев платины $\left(d_{\mathrm{Pt}}\right)$.

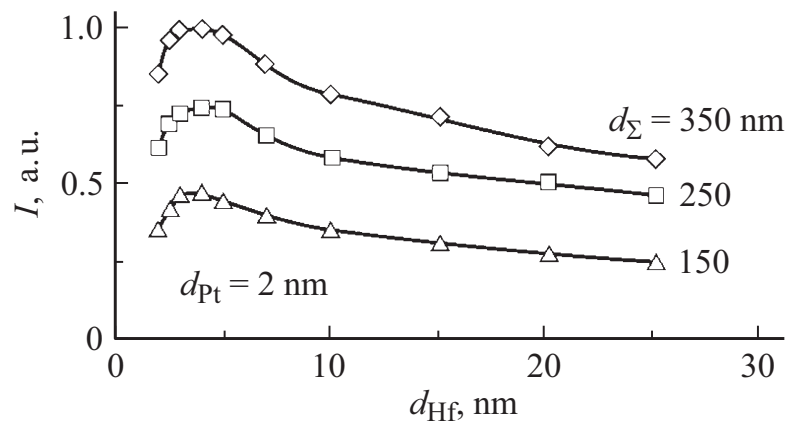

Рис. 5. Зависимости тока эмиссии $I$ от толщины слоев гафния $d_{\mathrm{Hf}}$, рассчитанные при одинаковой толщине слоев платины $d_{\mathrm{Pt}}=2 \mathrm{~nm}$ для катодов разной суммарной толщины $d_{\Sigma}$.

Из расчетов следует, что при суммарной толщине слоистой структуры 150-350 nm наибольшие токи эмиссии могут быть получены при толщинах слоев гафния $d_{\mathrm{Hf}} \sim 3-5 \mathrm{~nm}$. Например, при толщинах $d_{\mathrm{Pt}}=2 \mathrm{~nm}$ и $d_{\mathrm{Hf}}=5 \mathrm{~nm}$ катод, включающий 35 пар слоев и имеющий суммарную толщину $d_{\Sigma}$ около $250 \mathrm{~nm}$, согласно расчетам, обеспечивает на 20-30\% больший ток эмиссии, чем катод той же суммарной толщины, но с толщинами слоев платины и гафния соответственно 2 и $10 \mathrm{~nm}$.

\section{Экспериментальное исследование

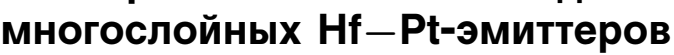

На рис. 6, а показано схематическое изображение слоистого катода. При создании эмиттеров в качестве подложки использовалась пластина из монокристалла арсенида галлия толщиной $430 \mu \mathrm{m}$ (1) с удельным сопротивлением не менее $10^{7} \Omega / \mathrm{cm}$. На боковую поверхность подложки последовательно наносилось 20 пар слоев Hf и Pt шириной $3.5 \mathrm{~mm}$ (2). Была исследована работа катодов $C 1$ и $C 2$ с разными толщинами слоев Hf, равными у этих катодов соответственно 5 и $10 \mathrm{~nm}$. Толщины слоев $\mathrm{Pt}$ у катодов $C 1$ и $C 2$ были одинаковы и равнялись $2 \mathrm{~nm}$. Чтобы снизить усиление поля, существующее у границы слоистых структур, и уменьшить связанную с этим неоднородность полевой эмиссии по сечению катода, последний (внешний) слой $\mathrm{Pt}$ имел увеличенную толщину $20 \mathrm{~nm}$. Для подачи напряжения на катод использовался нанесенный поверх слоистой структуры слой титана толщиной $200 \mathrm{~nm}$ (3). После создания многослойной системы монокристалл $\mathrm{GaAs}$ скалывался по кристаллографическому направлению, что обеспечивало атомарно ровный срез на эмитирующем торце катода.

Эмиссионные характеристики катодов исследовались с использованием измерительной системы, схематически изображенной на рис. $6, b$. Расстояние между катодом 1 и управляющим электродом 2 устанавливалось равным $1 \mathrm{~mm}$. Для получения полевой эмиссии на катод подавалось отрицательное относительно управляющего 
электрода постоянное напряжение $U$. Токи эмиссии измерялись в цепи коллектора 3 , выполненного в форме цилиндра Фарадея, а также в цепи управляющего электрода 2. Для регистрации изменений тока во времени использовался электронный самописец 5 типа Velleman PCS10.

Вакуумная камера, использованная для исследования слоистых катодов, подвергалась непрерывной откачке с помощью магнитно-разрядного насоса. После установки в вакуумную камеру катоды подвергались тренировке с отбором тока в течение нескольких часов при увеличенном давлении $10^{-6}-10^{-7}$ Torr. Исследование эмиссионных характеристик катодов производилось при давлениях остаточного газа $(2-5) \cdot 10^{-8}$ Torr.

Типичные экспериментально измеренные вольт-амперные характеристики катодов $C 1$ и $C 2$ представлены на рис. 7. В исследованном интервале напряжений катод $C 1$ обеспечивал ток эмиссии примерно до $300 \mu \mathrm{A}$. С катода $C 2$ был получен ток эмиссии более $2 \mathrm{~mA}$ при плотности тока около $200 \mathrm{~A} / \mathrm{cm}^{2}$. Сравнение результатов $a$

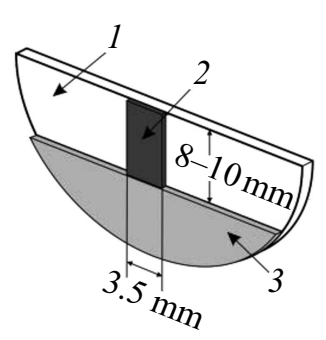

$b$

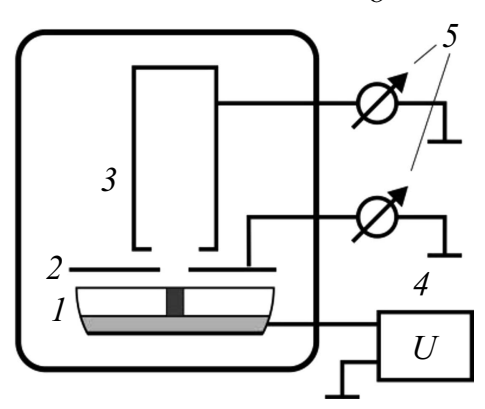

Рис. 6. $a-$ схематическое изображение многослойного катода: 1 - подложка из GaAs, 2 - многослойная система, 3 - Ті металлизация; $b-$ схематическое изображение сечения измерительной системы: 1 - катод, $2-$ управляющий электрод, 3 - коллектор, 4 - источник стабилизированного постоянного напряжения $U, 5-$ измерительная аппаратура.

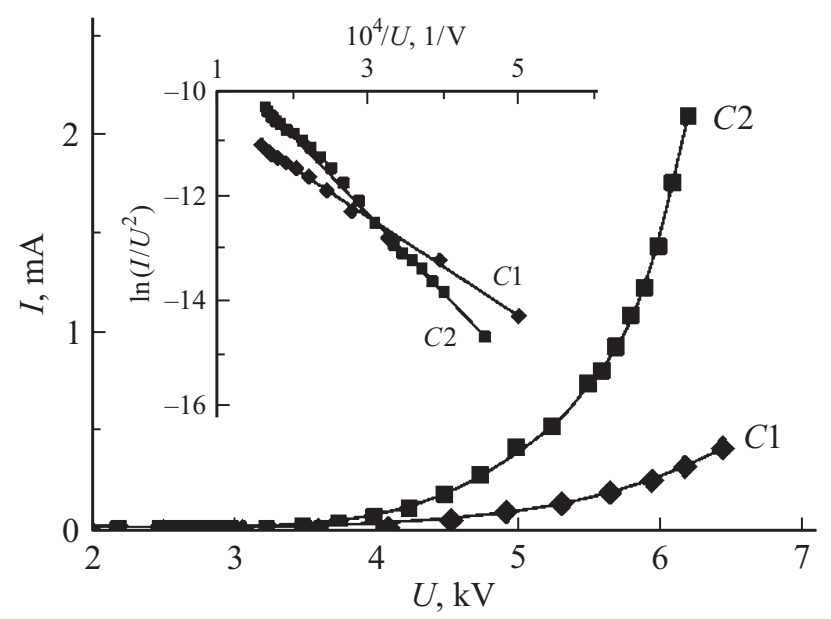

Рис. 7. Вольт-амперные характеристики и характеристики Фаулера-Норгейма катодов $C 1$ и $C 2$.

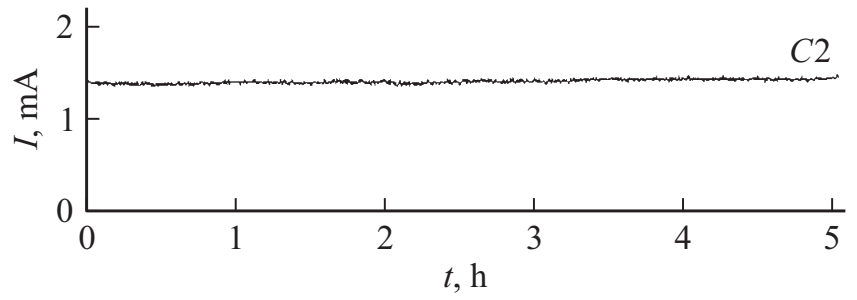

Рис. 8. Зависимость тока эмиссии катода $C 2$ от времени: $U=6 \mathrm{kV}$.

проведенных измерений с результатами выполненных расчетов позволили оценить ширину переходной области $l$. Наилучшее совпадение расчетов с экспериментальными данными имеет место при $l=0.51 \mathrm{~nm}$.

Для оценки возможности стабильной эксплуатации слоистых катодов измерялись изменения тока эмиссии во времени. На рис. 8 показана типичная зависимость $I(t)$, измеренная для катода $C 2$ при начальном токе $\sim 1.4 \mathrm{~mA}$.

\section{Расчет характеристик составного катода}

Исследованные слоистые катоды малой площади $\left(\sim 10^{-5} \mathrm{~cm}^{2}\right)$ обеспечивали токи полевой эмиссии, не превосходящие единиц $\mathrm{mA}$. Между тем во многих приложениях необходимы токи порядка десятков $\mathrm{mA}$ или даже более [8]. Кратное увеличение токов принципиально возможно при использовании „составной“ катодной системы, включающей более одного многослойного катода.

При объединении в одну катодную систему нескольких многослойных структур важно обеспечить условия, когда в заданной диодной системе с плоским анодом близки по величине электрические поля у торцевой (эмитирующей) поверхности всех эмиттеров в составном катоде. Для определения таких условий были проведены расчеты для составного катода, включающего четыре многослойных эмиттера. Схематическое изображение рассматриваемого катода приведено на рис. 9. Катод состоит из 4 многослойных структур (1-4), нанесенных на 3 подложки из GaAs одинаковой толщины $430 \mu \mathrm{m}$. На центральную подложку многослойные структуры нанесены с обеих сторон. Для обеспечения приблизительно одинакового поля у поверхности всех многослойных структур центральная подложка приподнята над соседними на величину $\Delta$. Для определения величины $\Delta$ и тока эмиссии составного катода были проведены расчеты для катода, имеющего следующие параметры: все 4 многослойные структуры включают по 20 пар слоев Hf и $\mathrm{Pt}$ толщиной соответственно $d_{\mathrm{Hf}}=10 \mathrm{~nm}$ и $d_{\mathrm{Pt}}=2 \mathrm{~nm}$. Расстояние между плоским анодом и центральной подложкой $1 \mathrm{~mm}$. 


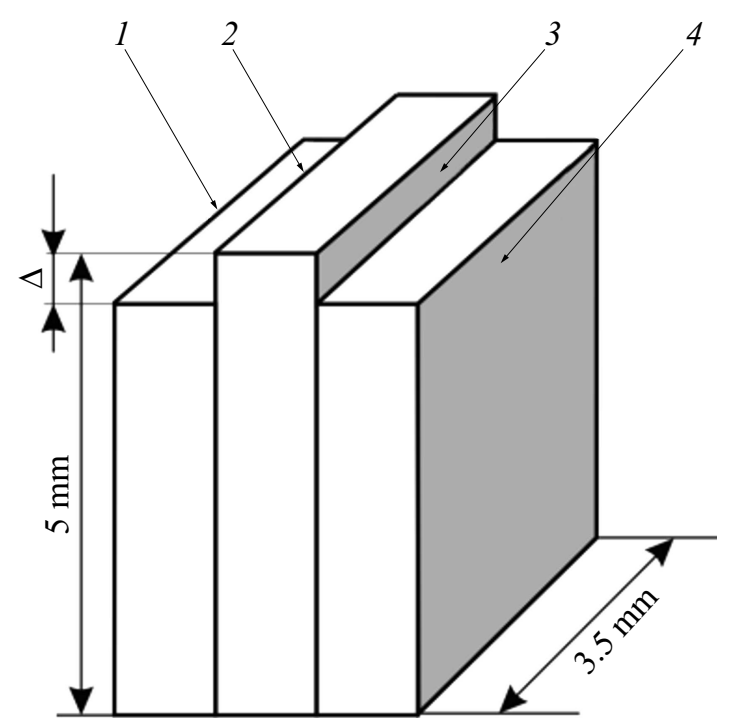

Рис. 9. Схематическое изображение составного катода: $\Delta-$ высота вылета центральной подложки, $1-4-$ слоистые системы.

При этих параметрах оптимальная высота $\Delta$ возвышения центральной подложки, обеспечивающая равенство полей у торца всех включенных в составной катод слоистых структур, равна $220 \mu \mathrm{m}$. Суммарный ток эмиссии $I$ для данного составного катода при напряжении $U=10 \mathrm{kV}$ достигал значения около $10 \mathrm{~mA}$. Таким образом, проведенные расчеты свидетельствуют о существовании больших резервов повышения токов полевой эмиссии при создании составных катодов.

\section{Заключение}

Подытоживая проведенные исследования, отметим важнейшие полученные результаты:

- в расчетах, учитывающих существование переходных зон в области контакта материалов с разной работой выхода, оптимизирована структура многослойных гафний-платиновых катодов;

- экспериментально исследована работа гафнийплатиновых катодов и продемонстрирована возможность стабильной их работы при отборе с эмитирующей поверхности катода площадью $\sim 10^{-5} \mathrm{~cm}^{2}$ токов полевой эмиссии $\sim 2-2.5 \mathrm{~mA}$ при плотностях тока приблизительно до $200 \mathrm{~A} / \mathrm{cm}^{2}$;

- продемонстрирована возможность создания составных катодов, включающих несколько слоистых эмитирующих структур и обеспечивающих кратное увеличение токов эмиссии по сравнению с одиночным многослойным катодом.

Исследованные многослойные катоды перспективны для использования в миниатюрных высоковольтных электронных приборах, работающих в условиях технического вакуума.
Работа финансировалась Российским научным фондом (проект № 16-12-10010).

\section{Список литературы}

[1] Соминский Г.Г., Сезонов В.Е., Саксеев Д.А., Тумарева Т.A. // ЖТФ. 2011. Т. 81. Вып. 6. С. 104-108.

[2] Sominski G.G., Sezonov V.E., Taradaev E.P., Tumareva T.A., Zadiranov Yu.M., Kornishin S.Yu., Stepanova A.N. // Radiophys. Quant. El. 2015. Vol. 58. N 7. P. 511-519.

[3] Соминский Г.Г., Сезонов В.Е., Задиранов Ю.М. // НТВ СПбГПУ. Физико-математические науки. 2015. Вып. 3. C. $48-53$.

[4] Sominskii G., Sezonov V. // Proc. of the $14^{\text {th }}$ Baltic Conf. on Atomic Layer Deposition. St. Petersburg, Russia, 2016. P. 63.

[5] Журавель И.А., Бугаев Е.А., Девизенко А.Ю., Першин Ю.П., Кондратенко В.В. // Физическая инженерия поверхности. 2011. Т. 9. Вып. 2. С. 134-141.

[6] Журавель И.А., Бугаев Е.А., Конотопский Л.Е., Севрюкова В.А., Зубарев Е.Н., Кондратенко В.В. // ЖТФ. 2014. Т. 84. Вып. 5. С. 71-77.

[7] Авторефб. канд. дис. Е.А. Вишняков. МФТИ, 2013. 132 с.

[8] Glyavin M.Yu., Manuilov V.N., Sominskii G.G., Taradaev E.P., Tumareva T.A. // Infrared Phys. Techn. 2016. Vol. 78. P. 185189. 